\title{
Changes in Sugar Nucleotide and High Energy Phosphate Kinetics during In Vivo Development of Sponge Biopsy Connective Tissue *
}

\author{
Giles G. Bole $†$ with the technical assistance of Janet C. Leutz \\ (From the Rackham Arthritis Research Unit, Department of Internal Medicine, The University \\ of Michigan, Ann Arbor, Mich.)
}

Connective tissue varies widely in its histological appearance and chemical composition. Its physical state ranges from the hardness of bone to the viscous mucopolysaccharides found in synovial fluid. Current evidence would indicate that the special fibrillar and other extracellular constituents are formed by the cells of the connective tissue (1). Certain of these constituents have been shown to change with age $(2,3)$, nutritional status $(4,5)$, and during experimental propagation in vivo (6). Observations of this type suggest that physiological factors that regulate the functional state of connective tissue may be directly associated with the chemical intermediates leading to de novo synthesis of these cell products. The $5^{\prime}$-ribonucleotides ${ }^{1}$ have been

\footnotetext{
* Submitted for publication April 1, 1966; accepted August 12, 1966.

This study was supported by grant AM 06206 from the National Institutes of Health, U. S. Public Health Service. The Rackham Arthritis Research Unit is supported by a grant from the Horace H. Rackham School of Graduate Studies. A preliminary report of this work has been published (Arthr. and Rheum. 1963, 6, 793).

$\dagger$ Senior Investigator, Arthritis Foundation.

Address requests for reprints to Dr. Giles G. Bole, The Rackham Arthritis Research Unit, The University of Michigan, University Hospital, Ann Arbor, Mich.

1 The following abbreviations are used: AMP, ADP, ATP, CMP, CDP, CTP, GMP, GDP, GTP, UMP, UDP, UTP for the $5^{\prime}$-mono-, di-, and triphosphates of adenosine, cytidine, guanosine, and uridine; UDP-G for uridine diphosphate glucose; UDP-Gal for uridine diphosphate galactose; UDP-hexose for unresolved mixtures of UDP-G and UDP-Gal ; UDP-AcGm for uridine diphosphate-N-acetyl-D-glucosamine; UDP-AcGalm for uridine diphosphate- $\mathrm{N}$-acetyl-D-galactosamine; UDP$\mathrm{AcHm}$ or UDP-N-acetyl-hexosamines for an unresolved mixture of UDP-AcGm and UDP-AcGalm; UDP-GA for UDP-D-glucuronic acid; GDP-M for guanosine diphosphate mannose; GDP-Fu for guanosine diphosphate fucose; GDP-X for a guanosine diphosphate monosaccharide; GDP-hexose for the total amount of GDP-M,
}

shown to be essential to the anabolic synthesis of proteins (7), polysaccharides (8), and lipids (9). The monosaccharide sugar nucleotides are the precursors presumed to be involved in the biosynthesis of mucopolysaccharides, glycoproteins, and glycolipids $(8,10,11)$. In several experimental systems (12) these intermediates have been shown to be involved in formation of the products of connective tissue cells, and partial characterization of nucleotides present in carrageenin granulomas has been made by Decker and Gross (13).

In the current study, the $5^{\prime}$-ribonucleotides present in acid soluble extracts of 14-, 28-, and 42day sponge biopsy connective tissue have been isolated and identified. This time interval spans the most active period of connective tissue organization of subcutaneously implanted polyvinyl sponge in experimental animals (14). The content of UDP-N-acetylhexosamines was found to increase with tissue age, whereas the concentration of UDP-hexoses and GDP-hexoses decreased between 14 and 42 days. No significant shift in the per cent composition of the other $5^{\prime}$-ribonucleotides was demonstrated. The incorporation of ${ }^{32} \mathrm{P}$-orthophosphate into purine and pyrimidine nucleotides was also studied at each tissue age.

\section{Methods}

Production of inflammatory connective tissue in guinea pigs. The technique involved in implantation and removal of polyvinyl sponge granulomas and the morphologic characteristics of the tissue have been previously described (14). Four sponge implants $(0.5 \times 2 \times 2 \mathrm{~cm})$ were made in the low dorsolumbar area of adult mongrel guinea pigs ( 650 to $800 \mathrm{~g}$ ) ; 15 to 20 animals were used

GDP-Fu, and GDP-X; $P_{\mathbf{t}}$ for inorganic phosphate; $P_{t}$ for total phosphate. In initial fractionation $A 260=a b-$ sorbance of ultraviolet (UV) light at $260 \mathrm{~m} \mu$ in a $1-\mathrm{cm}$ light path $\times$ total volume in milliliters. 
in each experiment. Two groups of animals were studied at 14 days, and one group was studied at 28 and at 42 days. Weight of the animals was determined every 3 days throughout the period of experimental observation, and individual animals were excluded from the study unless weight stability or gain was recorded. Each animal's drinking water was supplemented with ascorbic acid for 5 days after implantation of the polyvinyl sponges. Four hours before removal of the implants, $5 \mu \mathrm{c}$ of $\mathrm{Na}_{2} \mathrm{H}^{22} \mathrm{PO}_{4}$ was injected into each of the granulomas.

Preparation and fractionation of the acid soluble tissue extract. The sponge implants were rapidly removed from each animal, cut into small fragments, and placed directly into an equal volume of cold $\left(4^{\circ} \mathrm{C}\right) 10 \%$ trichloroacetic acid. Wet weight of the total tissue mass was determined, and all subsequent operations were carried out at $4^{\circ} \mathrm{C}$. The implants were homogenized in a Waring blendor for 5 minutes. The supernatant was filtered through a coarse scintered glass funnel and the residue re-extracted with an equal volume of $5 \%$ trichloroacetic acid. The total extract was combined and the final acid soluble fraction obtained after repeating the filtration. Trichloroacetic acid was removed by three successive extractions with equal volumes of diethyl ether. The volume of water soluble material was measured and absorbance at $260 \mathrm{~m} \mu$ (A260) and $280 \mathrm{~m} \mu$ determined in a Beckman DU spectrophotometer. Analyses for inorganic phosphorus, total phosphorus (15), adenine (16), and protein (17) were carried out on portions of this material. Preliminary fractionation of the extract was accomplished by stepwise gradient elution from a Dowex 1 (formate) $x-8,200$ - to 400 -mesh resin column $30 \times 1.9 \mathrm{~cm}$ in size. The column was washed with $400 \mathrm{ml}$ distilled water followed by elution with increasing concentrations of formic acid and ammonium formate in formic acid as described by Denamur, Fauconneau, and Guntz (18). Serial $15-\mathrm{ml}$ fractions were collected on an automatic fraction collector, and the A260 of each fraction was determined. One-ml samples from each fraction tube were removed for measurement of radioactivity. The presence of Ninhydrin reactive material in the column fractions before the addition of ammonium formate to the eluent was determined on $0.05-\mathrm{ml}$ samples after they were applied to Whatman 1 paper (19).

Appropriate fractions were pooled, and the $\mathrm{pH}$ of the pooled eluates was adjusted to 4.5 with $\mathrm{NH}_{4} \mathrm{OH}$. This material was absorbed on $30-\times 1.9-\mathrm{cm}$ columns of coarse SGL acid-washed charcoal. 2 The columns were washed with 500 to $1,000 \mathrm{ml}$ of distilled water, and this was promptly followed by the rapid elution of the charcoal columns with $4 \% \mathrm{NH}_{4} \mathrm{OH}$ in $50 \%$ ethanol (vol/vol). The total volume of eluting solution was determined by repetitive measurement of A260 material present in the eluate. The ammoniacal-ethanol eluates were concentrated to dryness by rotary evaporation at $25^{\circ} \mathrm{C}$. The dried material was redissolved in a small volume of dis-

2 Pittsburgh Coke and Chemical Co., Pittsburgh, Pa. The charcoal was prepared according to the procedure of Bartlett (20). tilled water, and final purification and separation of the individual nucleotides were accomplished by paper chromatography. After application to Whatman 3-mm paper, descending chromatography was carried out with isobutyric acid: concentrated ammonium hydroxide: water (57:4:39), pH 4.3. The ultraviolet-absorbing bands were identified, eluted with water, and concentrated, and each one was rechromatographed with $95 \%$ ethanol: 1.0 $\mathrm{M}$ ammonium acetate $(70: 30), \mathrm{pH} 7.4$. The ultravioletabsorbing bands were again eluted with distilled water; these eluates were used to identify the individual nucleotides.

Identification of $5^{\prime}$-ribonucleotides. The mobilities $\left(R_{\mathfrak{f}}\right)$ of the nucleotides separated by paper chromatography were compared with the mobility of standard $5^{\prime}$-ribonucleotides ${ }^{3}$ chromatographed as marker compounds on the same chromatogram. Total absorbance at $260 \mathrm{~m} \mu$ was determined for each component, and ultraviolet absorption spectra at $\mathrm{pH} 1.5,5$, and 11 were determined in a Cary model 14 recording spectrophotometer. The purine or pyrimidine base was identified by the characteristic spectral shifts that occur at these $\mathrm{pH}$ values. After we had previously determined total absorbance at $260 \mathrm{~m} \mu$ for each component and identified the base present in each, we used the appropriate molar absorbancy index (21) to calculate the molar concentration of each nucleotide isolated from the tissue. NAD was identified by its absorption spectrum and the characteristic spectral shifts in absorption maxima that occur at 260 and $327 \mathrm{~m} \mu$ after the addition of cyanide. Samples from the same preparations were analyzed for phosphorus by the FiskeSubbarow method as modified by Hurlbert, Schmitz, Brumm, and Potter (15). Susceptibility of these nucleotides to enzymatic hydrolysis by $5^{\prime}$-nucleotidase present in Crotalus adamanteous venom was carried out according to the method of Heppel and Hilmoe (22). To assay mono-, di-, and triphosphate nucleotides, we employed a 100fold excess in enzyme concentration to simultaneously utilize the pyrophosphatase as well as the $5^{\prime}$-nucleotidase activity of the venom (11). One-hour incubations were analyzed for inorganic and total phosphorus (15), and zero time incubations served as controls.

Characterization and identification of sugar nucleotides. In this study $0.2-\mu$ mole portions of all uridine, guanosine, and cytidine nucleotides having a mobility on final preparative paper chromatography similar to the respective sugar nucleotide standards were hydrolyzed with $0.01 \mathrm{~N} \mathrm{HCl}$ at $100^{\circ}$ for 15 minutes. The hydrochloric acid was removed by lyophilization and the hydrolysate analyzed chromatographically as shown in Figure 1. Appropriate sugar nucleotides and $5^{\prime}$-ribonucleotides were applied on the same chromatograms as reference

3 The reference 5'-mono-, di-, and triphosphate nucleotides, nucleosides, bases, and UDP-glucose used in the present study were obtained commercially (Pabst Laboratories, Milwaukee, Wisc.). The ${ }^{14} \mathrm{C}$-labeled UDP-Nacetyl-D-glucosamine, UDP-N-acetyl-D-galactosamine, and guanosine diphosphate mannose were kindly supplied by Dr. Saul Roseman and his associates, Rackham Arthritis Research Unit, The University of Michigan. 
ETHANOL: AMMONIUM ACETATE 7:3. PH 7.4

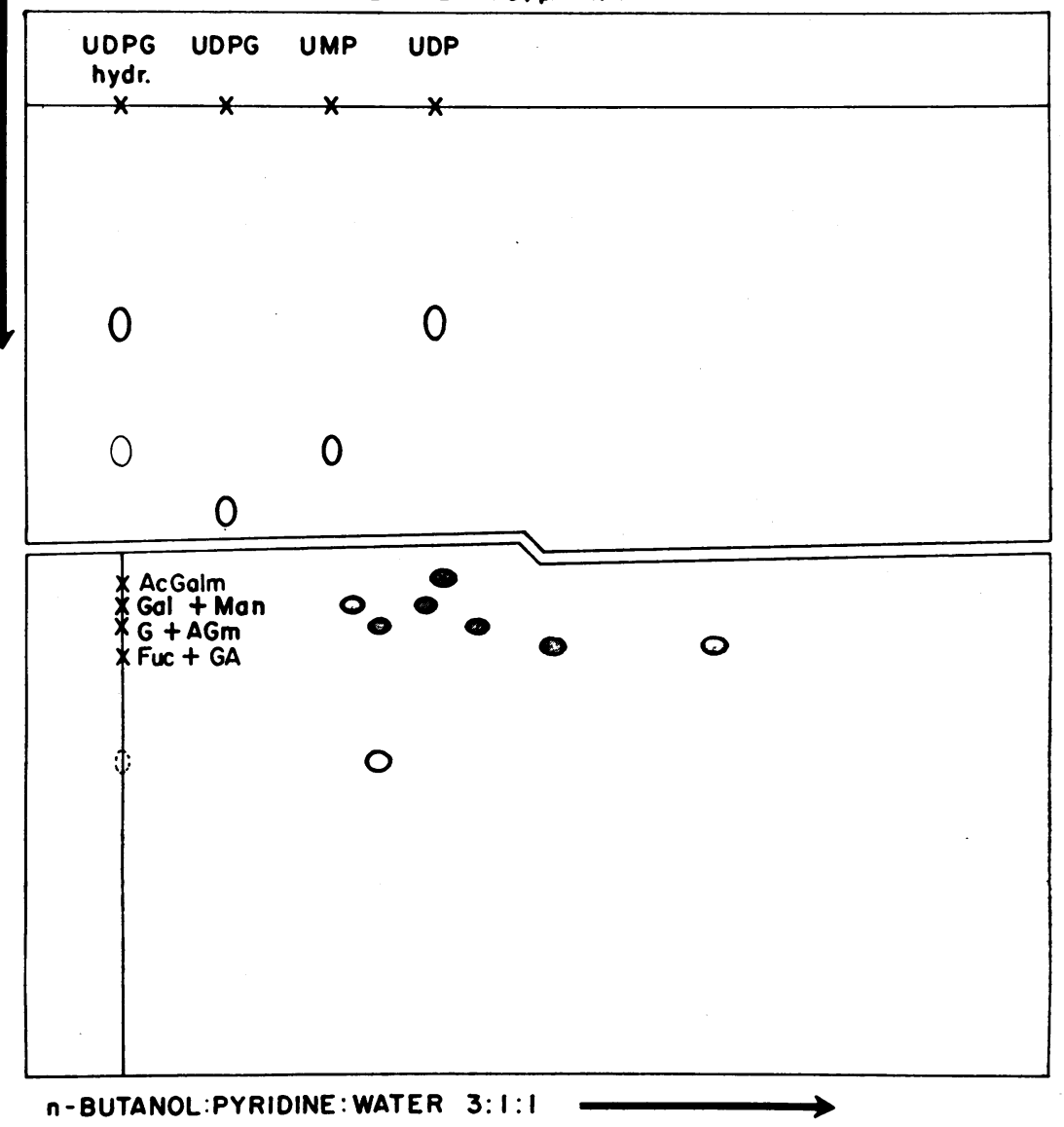

Fig. 1. Two DIMENSIONAL PAPER CHROMATOGRAPHy FOR IDENTIFICATION OF SUGAR NUCLEOTIDES. Diagrammatic presentation of the method of 2 dimensional paper chromatography (Whatman 3-mm) employed in preliminary identification of sugar nucleotides. In this instance $0.2-\mu$ mole samples of uridine diphosphate glucose (UDPG), UDPG hydrolyzed in $0.01 \mathrm{~N} \mathrm{HCl}$ at $100^{\circ} \mathrm{C}$ for 15 minutes (UDPG, hydr.), uridine monophosphate (UMP), and UDP were chromatographed 16 hours by descending technique using 95\% ethanol:ammonium acetate $(7: 3), \mathrm{pH} 7.4$. The dried chromatogram was examined under ultraviolet light and demonstrated the release of UDP after mild acid hydrolysis with disappearance of UDPG. Trace amounts of UMP were occasionally noted in the hydrolyzed specimen. The chromatogram was cut horizontally and the distal $24 \mathrm{~cm}$ prepared for descending chromatography using $n$-butanol: pyridine: water $(3: 1: 1)$ for 8 hours, dried, and redeveloped for 16 hours. The following standards were included at the margin: N-acetyl-D-galactosamine (AcGalm) ; galactose (Gal) ; mannose (Man) ; glucose (G) ; N-acetyl-D-glucosamine (Ac$\mathrm{Gm}$ ) ; fucose (Fuc); and glucuronic 3,6-lactone (GA). Their mobilities after chromatography are indicated by shaded circles: Gal $<\mathrm{G}<\mathrm{Man}<\mathrm{AcGm}<\mathrm{Fuc}<\mathrm{GA}$. The broken circle at the origin identifies the position of the acyl-sugar released by mild acid hydrolysis after initial chromatography in ethanol:ammonium acetate, and the open circle corresponding in mobility to glucose identifies the specific sugar after chromatography in $n$-butanol: pyridine: water $(3: 1: 1)$. The sugars were detected by a periodate-benzidine reaction (23). All unknown specimens were originally examined by this technique. Those demonstrating release of an acyl-sugar and appearance of the appropriate nucleotide diphosphate under conditions of mild acid hydrolysis were further characterized as described in the text. 
compounds. Further characterization of the monosaccharide present in the sugar nucleotides identified by this procedure was accomplished by chromatography of additional samples after mild acid hydrolysis. The hydrolysates were deionized with mixed bed resin [equal quantities of Dowex $50(\mathrm{H})$ and Dowex $1\left(\mathrm{HCO}_{3}\right), 20$ to 40 mesh], and the filtrates were concentrated to a small volume. Acetylhexosamines were separated by electrophoresis and detected with an alkaline-ethanol spray reagent as described by Jourdian and Roseman (24). Hexoses and acetylhexosamines were separated on Whatman 1 paper with the following solvent systems: n-butanol : pyridine: $0.1 \mathrm{~N} \mathrm{HCl}(5: 3: 2)$, $n$-butanol: pyridine: water $(3: 1: 1)$, and ethyl acetate: pyridine: water $(10: 4: 3)$. The sugars were detected with a silver nitrate reagent $(24)$.

A $2.0-\mu$ mole sample of the UDP-N-acetylhexosamines isolated from 14-day tissue was hydrolyzed with $2 \mathrm{~N} \mathrm{HCl}$ at $100^{\circ} \mathrm{C}$ for 3 hours (25). The hydrolysate was $1 \mathrm{y}$ ophilized, redissolved in distilled water, and applied to a 46- $\times 1-\mathrm{cm}$ Dowex $50(\mathrm{H}) 200$ - to 400 -mesh column from which the individual hexosamines were eluted with $0.3 \mathrm{~N}$ $\mathrm{HCl}$ as described by Gardell (26). After fractionation the amount of glucosamine and galactosamine was determined by colorimetric analysis (27). Complete separation of the two hexosamines was confirmed by paper chromatography of samples from the two column peaks.

Radioactivity determinations. Samples from the initial extract, column fractions, and final chromatographic components were dried on metal planchets before measurement of radioactivity. A thin window gas flow counter was used for all determinations of ${ }^{2} \mathrm{P}$ radioactivity.
Counting efficiency was such that $1 \mu \mathrm{c}$ was equal to $8.0 \times$ $10^{5} \mathrm{cpm}$. Counting of the individual specimens was carried out for sufficient time so that the error of counting was less than $3 \%$. Specific activities were calculated after a correction for ${ }^{32} \mathrm{P}$ decay. Internal standards were employed and all experiments corrected when mecessary to the same level of measured radioactivity.

\section{Results}

Characterization and purification of acid soluble extracts. Sponge biopsy connective tissue was studied at 14,28 , and 42 days. During this interval, connective tissue ingrowth progresses from partial to complete penetration of the subcutaneously implanted polyvinyl sponge. In each of these experiments, implants from 15 to 20 animals were pooled so that the total connective tissue mass available for extraction with cold trichloroacetic acid was 60 to $100 \mathrm{~g}$ net wet weight. As demonstrated in previous studies (14) and confirmed in this investigation, the water content of 14- to 42-day granulomas was $88 \pm 1 \%$ of tissue wet weight. Net tissue wet weight was used to compare the various chemical analyses at 14,28 , and 42 days.

Figure 2 illustrates the elution pattern of A260 material and radioactivity after fractionation by

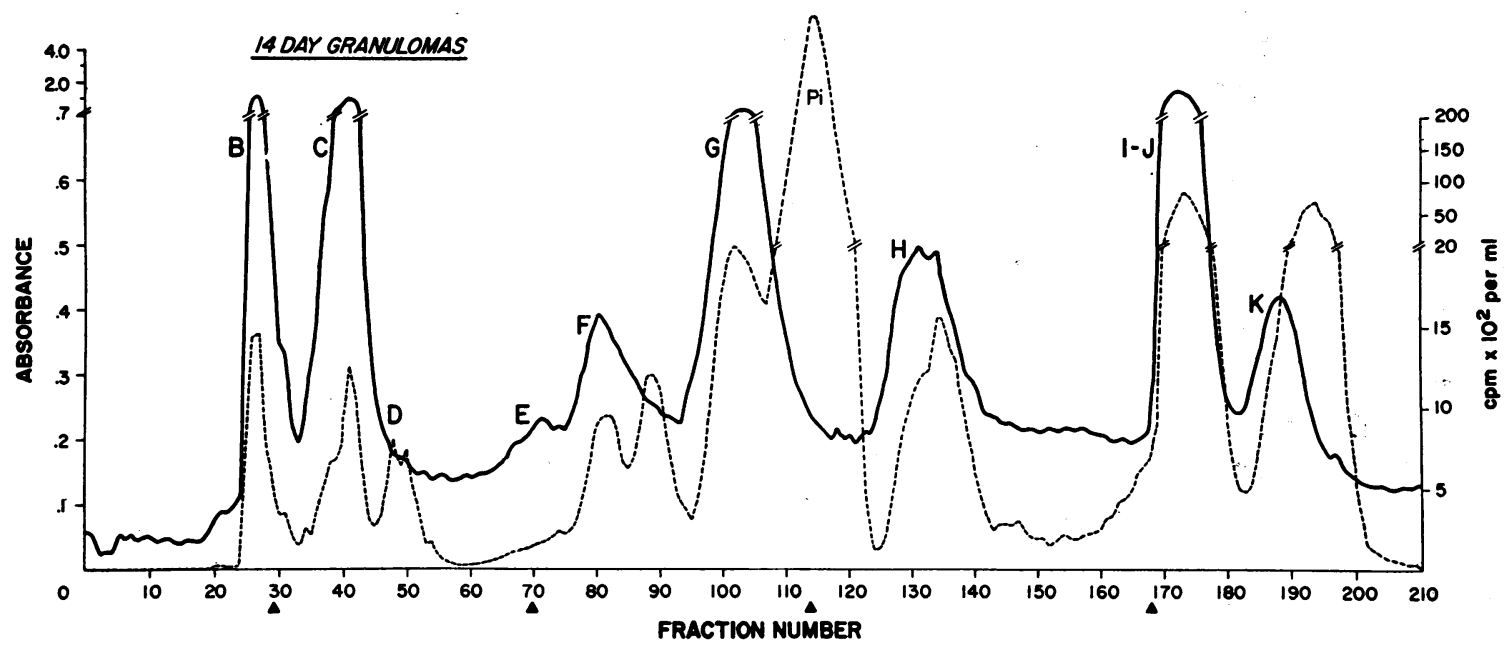

Fig. 2. Dowex 1 (formate) gradient elution column chromatography. Pattern of elution of nucleotides present in an acid soluble extract of $70.6 \mathrm{~g}$ of 14-day sponge biopsy connective tissue. The $5^{\prime}$-nucleotides present in peaks $\mathrm{B}$ to $\mathrm{K}$ are identified in Table II. Absorbance at $260 \mathrm{~m} \mu$ per $\mathrm{ml}$ (solid line), and ${ }^{32} \mathrm{P}$ radioactivity counts per minute per milliliter (broken line) were determined on each $15-\mathrm{ml}$ fraction tube. After elution with $400 \mathrm{ml}$ distilled water, stepwise changes in the eluent were made at the points indicated on the abscissa: $1 \mathrm{~N}$ formic acid, tube $0 ; 4 \mathrm{~N}$ formic acid, tube $29 ; 0.2 \mathrm{~N}$ ammonium formate in $4 \mathrm{~N}$ formic acid, tube $70 ; 0.4 \mathrm{~N}$ ammonium formate in $4 \mathrm{~N}$ formic acid, tube 114 ; and $1.6 \mathrm{~N}$ ammonium formate in $4 \mathrm{~N}$ formic acid, tube 167 . $\mathrm{P}_{1}$ indicates the presence of inorganic ${ }^{32} \mathrm{P}$ in the eluate. 
ion exchange chromatography of one of the acid soluble extracts from 14-day tissue. Six major and two minor peaks were identified by the changes in absorbance at $260 \mathrm{~m} \mu$. In general, the elution of radioactivity paralleled that for A260 material although an additional peak D and at least two radioactive components were present in peak $\mathrm{F}$. Unincorporated inorganic ${ }^{32} \mathrm{P}$ $\left(P_{i}\right.$, Figure 2$)$ accounted for the large radioactive peak eluted from the column between peaks $G$ and $\mathrm{H}$. Column chromatographic fractionations of the acid soluble extracts from 28- and 42-day tissue were similar to that found with 14-day tissue. With the exception of peak I-J, the total amount of radioactivity decreased 20 to $30 \%$ in the other peaks between 14 and 42 days. The nucleotide composition of these column fractions will be discussed in detail subsequently. Small amounts of NAD and Ninhydrin reactive material were detected in the fraction tubes corresponding to peak $B$ at 14,28 , and 42 days.

Using known mixtures of standard 5'-ribonucleotides, we achieved quantitative recovery with the formic acid-ammonium formate system. Under the conditions employed in these studies complete resolution of individual nucleotide constituents was not accomplished by the initial step employing ion exchange chromatography. We elected to collect $15-\mathrm{ml}$ fractions and to isolate the individual nucleotides after further purification by charcoal column and paper chromatography. As reported by others $(15,18)$, nucleotide monophosphates were found in small quantities in peaks $F$ to $K$, indicating that some degradation of nucleotide di- or triphosphates had occurred during column fractionation. In all of the experiments we found that more than $95 \%$ of the total A260 material present in the original acid soluble extract was absorbed to the ion exchange resin and eluted during fractionation. After absorption and elution from charcoal, 70\% of this A260 material was present in the ammoniacal-ethanol eluates. This apparent loss was felt to represent primarily the exclusion of peptides and non-nucleotide materials in these early steps of purification. Comparison of A260 of the total material eluted from the charcoal columns with that recovered after the final step of paper chromatography was found in all experiments to be $79 \% \pm 9 \%$. The molar concentra- tions of total, individual, and sugar nucleotides per $100 \mathrm{~g}$ of tissue have been calculated after application of the appropriate molar absorbancy indexes (21).

Measurements of radioactivity were carried out at each step during fractionation and purification. In the 14-day study, $9 \%$ of the initial radioactivity present in the crude acid soluble extract was shown to be present in $5^{\prime}$-nucleotides, $11.5 \%$ at 28 days, and $10 \%$ at 42 days. In each experiment the major source of non-nucleotide radioactivity was present in the trailing limb of peak G. In the other fractions separated by ion exchange chromatography, more than $84 \%$ of the radioactivity in each peak was ultimately recovered in the $5^{\prime}$-nucleotides. When the material from peak $\mathrm{G}$ was applied to the charcoal columns at $\mathrm{pH} 4.5,94 \%$ of the radioactivity was not absorbed and was removed from the column by a preliminary wash with distilled water. Some of this labeled material could represent uncharacterized sugar phosphates; however, migration on paper chromatography in two solvent systems corresponded with that of inorganic ${ }^{32} \mathrm{P}$.

Qualitative identification of 5'-nucleotide constituents. Migration in the final preparative paper chromatographic system was determined for each ultraviolet-absorbing band identified on the individual chromatograms. From these data $R_{f}$ values were determined and compared to those of standards run simultaneously in the same solvent systems. Good correlation was found among these values, the data obtained by spectral analysis, and the phosphorus to base ratios.

The spectral characteristics were determined for each of the ultraviolet-absorbing components after elution from the final paper chromatograms. In Figure 3 representative spectra of individual nucleotides isolated from 14-day experiment 2 are compared with standard 5 '-nucleotide monophosphates. The unknowns $\mathrm{H}_{22}$ and $\mathrm{J}_{72}$ had the spectral absorption characteristics of adenosine and uridine, respectively. Specimen $\mathrm{K}_{62}$ had an acid-base shift in absorption maximum characteristic of guanosine, but anomalies in the minima were noted due to the presence of unidentified impurities. This specimen was chosen for graphic presentation as an example of the minimal spectral characteristics acceptable for unknowns included in this study. After spectral identifica- 


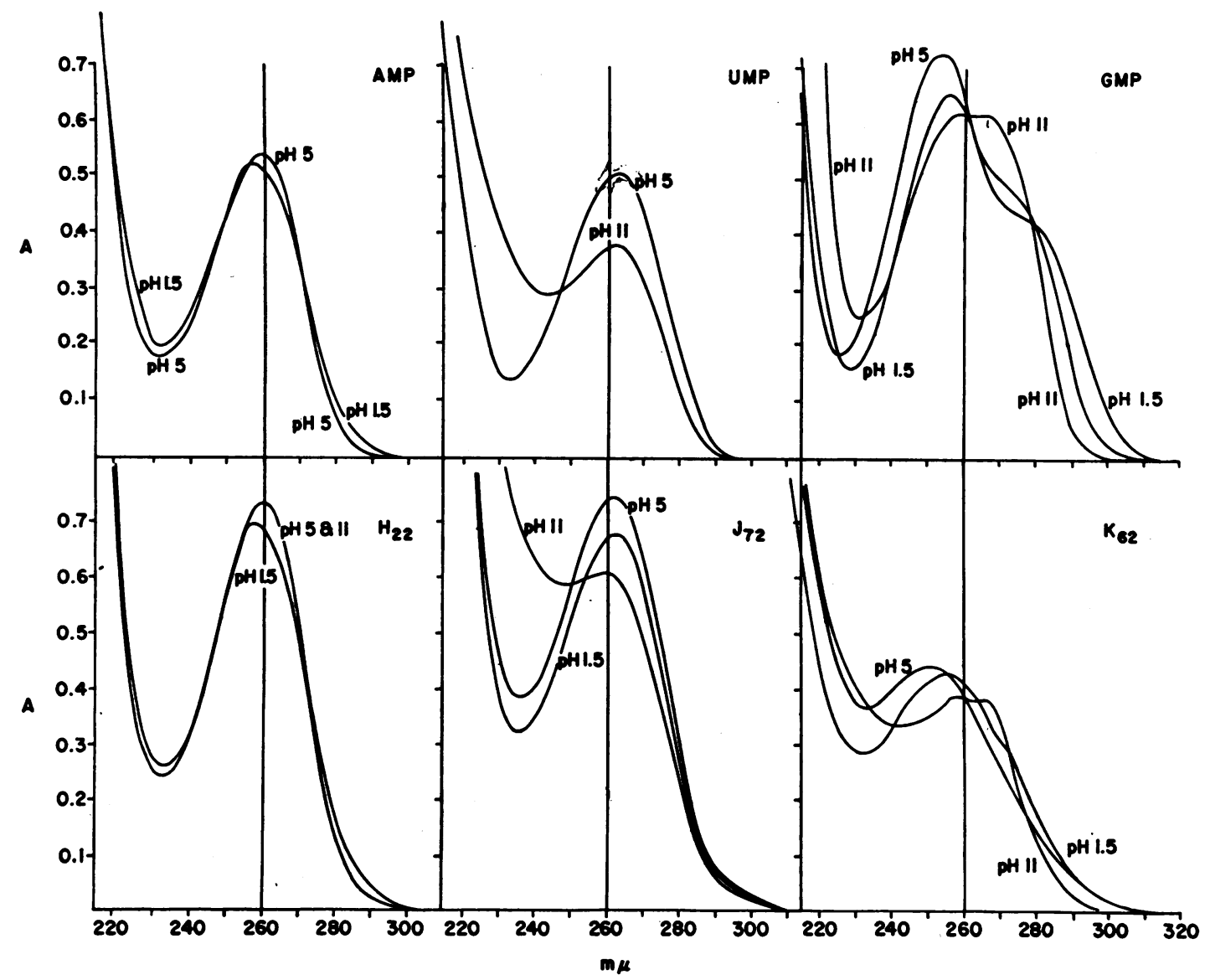

Fig. 3. Ultraviolet abSORPtion SPECTRA of $5^{\prime}$-RIBOnuCleotides. Spectra were determined in a Cary model 14 recording spectrophotometer. All components from final preparative paper chromatography were examined and spectral curves made at $\mathrm{pH} 1.5,5.0$, and 11. In the upper portion of the Figure, the spectra of adenosine monophosphate (AMP), UMP, and guanosine monophosphate (GMP) from a commercial source are compared with representative specimens in the lower portion from 14-day experiment 2 . The absorption maxima, minima, and $\mathrm{pH}$ shifts of $\mathrm{H}_{22}$ and $\mathrm{J}_{72}$ indicate adenosine and uridine. Sample $\mathrm{K}_{62}$ is included as an example of the minimal spectral characteristics acceptable for unknown specimens, in this instance guanosine. $\mathrm{A}=$ absorbance of ultraviolet light; $\mathrm{m} \mu=$ wavelength in millimicrons.

tion of the compound, the same sample was used to determine the total phosphorus content of the specimen.

Samples from all final fractions found to contain uridine, guanosine, or cytidine nucleotide were examined for sugar nucleotide content by two dimensional paper chromatography as illustrated in Figure 1. Employing this procedure, we identified uridine sugar nucleotides as major constituents of peak $\mathrm{H}$ from the Dowex 1 (formate) column fractionation (Figure 2). In the solvent system [95\% ethanol: $1.0 \mathrm{M}$ ammonium acetate $(7: 3), \mathrm{pH} 7.4]$ used for final separation and purification of 5 '-nucleotides UDP-glucose
+ UDP-galactose, $R_{\text {UMP }} 1.05$, and UDP-Nacetyl-D-glucosamine + UDP-N-acetyl-D-galactosamine, $R_{\text {JMP }} 1.12$, were resolved. In several instances after two dimensional paper chromatography a compound with an $R_{f}$ corresponding to glucuronic acid (lactone form) was identified. However, less than $0.16 \mu$ mole per $100 \mathrm{~g}$ was isolated from 14- to 42-day tissue. This small quantity precluded complete characterization of the intact parent uridine nucleotide. Guanosine diphosphate mannose, $R_{\text {UMP }} 0.94$, was the major guanosine sugar nucleotide identified. In all of the experiments small amounts of fucose and a hexose tentatively identified as glucose were 
found after acid hydrolysis and two dimensional paper chromatography of compounds present in peak F, G from the Dowex 1 (formate) column. Further characterization of these 5 '-monosaccharide nucleotides was accomplished by study of additional samples after mild acid hydrolysis, deionization with mixed bed resin, and paper chromatography in two other solvent systems that separate hexoses and $\mathrm{N}$-acetylhexosamines. The presence of both $\mathrm{N}$-acetylglucosamine and $\mathrm{N}$-acetylgalactosamine was also demonstrated qualitatively by borate electrophoresis after hydrolysis of amino sugar nucleotides isolated from 14-, 28-, and 42-day tissue (24). Quantitative separation of the free hexosamines on a Gardell column [Dowex $50(\mathrm{H})$ ] revealed that the molar ratio of glucosamine: galactosamine derived from amino sugar nucleotides in 14-day granulomas was $4: 1$.

Quantitative identification of 5'-nucleotide constituents. In Table I total 5'-nucleotide concentration per $100 \mathrm{~g}$ in the two 14-day experiments is compared to that found in 28- and 42-day sponge biopsy connective tissue. The values are based on a summation of the calculated molar concentration of the individual nucleotides isolated at each tissue age. Based on the variation noted at 14 days a slight increase in total $5^{\prime}$-nucleotide was observed at 28 and 42 days. Adenine nucleotides accounted for 40 to $43 \%$, uridine nucleotides for 42 to $45 \%$, guanosine nucleotides for 11 to $14 \%$, and cytidine nucleotides for less than $4 \%$ of the total $5^{\prime}$-nucleotide content. Chemical assay for total adenine present in the original crude acid soluble extracts was $54 \pm 4,72$, and $76 \mu$ moles per $100 \mathrm{~g}$ at 14,28 , and 42 days, respectively. When these values were arbitrarily corrected by taking into consideration the sequential losses of unidentified A260 material that occurred during purification, the amount of adenine nucleotide present in the final total $5^{\prime}$ nucleotide pool was 45 to $56 \%$. No significant shift in the per cent composition of total characterized nucleotides was demonstrated between 14 and 42 days.

During the period (14 to 28 days) of maximal cell growth, the concentration of total sugar nucleotide and UDP-N-acetylhexosamine increased (Table I). At 42 days the content of sugar nucleotides decreased from 12.4 to 5.6 $\mu$ moles per $100 \mathrm{~g}$. In spite of the decrease in total sugar nucleotides the amount of UDP-Nacetylhexosamines remained unchanged. As indicated by the ratios in Table I, the UDP-Nacetylhexosamines accounted for $46 \%$ of the total sugar nucleotide at 42 days, whereas a decrease in UDP-hexose (UDP-G + UDP-Gal), and GDP-hexose (GDP-M, GDP-Fu, GDP-X, or glucose) occurred in 42-day tissue. Trace amounts of UDP-D-glucuronic acid $(<0.16 \mu$ mole per $100 \mathrm{~g}$ ) were isolated from 14- to 42-day granulomas. Due to the small quantities recovered, chemical characterization of this nucleotide was incomplete, and it was not included in the calculations dealing with the content of sugar nucleotides in this tissue. No cytidine sugar nucleotides were identified in sponge biopsy connective tissue.

TABLE I

Comparison of 5'-ribonucleotide and sugar nucleotide content during in vivo development of sponge biopsy connective tissue*

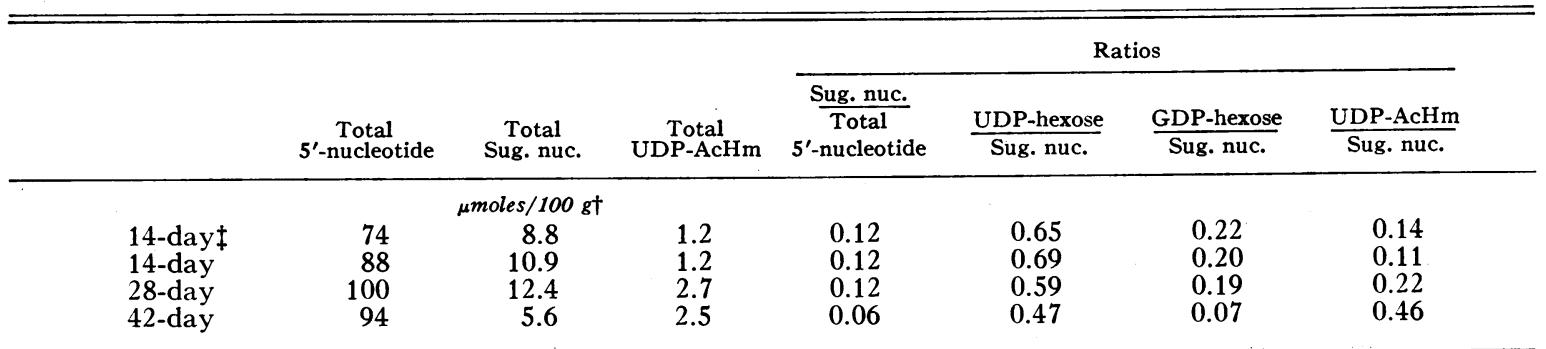

* Abbreviations: UDP = uridine diphosphate; $\mathrm{AcHm}=\mathrm{N}$-acetyl hexosamines; Sug. nuc. = sugar nucleotide; and GDP = guanosine diphosphate.

$\dagger$ Values are expressed as micromoles per $100 \mathrm{~g}$ wet weight of tissue. Water content was $88 \pm 1 \%$ at each tissue age. $\ddagger 14$-day experiments 1 and 2 . 
TABLE II

Characterization of 5'-ribonucleotides from 14-, 28-, and 42-day sponge biopsy connective tissue

\begin{tabular}{|c|c|c|c|c|}
\hline $\begin{array}{c}\text { Column } \\
\text { peak* }\end{array}$ & $\begin{array}{l}\text { Spectral } \\
\text { analysis } \dagger\end{array}$ & $\frac{\text { Phosphorus }}{\text { Base } \ddagger}$ & $\frac{\text { Inorganic } P}{\text { Total P§ }}$ & Identity\| \\
\hline & \multicolumn{4}{|c|}{ mean \pm observed range of values } \\
\hline $\mathrm{B}, \mathrm{C}$ & Adenosine & $1.01 \pm 0.08$ & $1.07 \pm 0.16$ & AMP \\
\hline $\mathrm{G}$ & Adenosine & $1.94 \pm 0.09$ & $0.89 \pm 0.12$ & $\mathrm{ADP}$ \\
\hline IJ & Adenosine & $3.05 \pm 0.18$ & $0.75 \pm 0.02$ & ATP \\
\hline $\mathrm{c}$ & Uridine & $1.04 \pm 0.24$ & $0.98 \pm 0.04$ & UMP \\
\hline G & Uridine & $1.86 \pm 0.12$ & 0.65 & UDP \\
\hline $\mathrm{IJ}, \mathrm{K}$ & Uridine & $2.86 \pm 0.06$ & 0.94 & UTP. \\
\hline $\mathrm{DE}$ & Guanosine & $1.10 \pm .012$ & 1.00 & GMP \\
\hline F & Guanosine & $1.91 \pm 0.17$ & 0.71 & GDP \\
\hline $\mathrm{K}$ & Guanosine & 2.89 & 0.94 & GTP \\
\hline $\mathrm{H}$ & Uridine & $2.09 \pm 0.15$ & $0.91 \pm 0.12$ & UDP-hexose \\
\hline $\mathrm{H}$ & Uridine & $1.91 \pm 0.12$ & 0.68 . & UDP-AcHm \\
\hline F,G & Guanosine & $2.01 \pm 0.20$ & 0.71 & GDP-hexose \\
\hline
\end{tabular}

* Predominate pattern of elution from Dowex 1 (formate) column. $\dagger$ Nucleoside identified by characteristic acid-base shift of absorption maxima and minima (21).

$\$$ Molar ratio of total phosphorus to purine or pyrimidine base.

$\$$ Ratio of net inorganic phosphorus $\left(\mathrm{P}_{\mathrm{i}}\right)$ to total phosphorus released

f enzymatic incubation with snake venom. See text for details.

II AMP, ADP, ATP, UMP, UDP, UTP, and GMP, GDP, and GTP are the $5^{\prime}$-mono-, di-, and triphosphates of adenosine, uridine, and guanosine, respectively.

Characterization of the 5 '-ribonucleotides identified in sponge biopsy connective tissue is presented in Table II, which summarizes the analyses carried out on individual constituents present in 14-, 28-, and 42-day tissue. The pattern of elution of these compounds during ion exchange chromatography is indicated by letters $B$ to $K$, which refer to the absorption peaks in Figure 2. The elution sequence corresponded with the anticipated behavior of mono-, di-, and triphosphate nucleotides when subjected to fractionation on a Dowex 1 (formate) resin column $(15,18)$. The mean total phosphorus to base ratio and observed range of values for the several 5 '-nucleotides demonstrated satisfactory agreement with the theoretical values. The mono-, di-, and triphosphate nucleotides of adenine and uridine were identified in all experiments. Identification of GMP and GDP in 28-day tissue was incomplete, and in the 42-day study GTP was only partially characterized. The sugar nucleotides UDP-G, UDP-Gal, UDP-AcGm, UDP-AcGalm, GDP-M, GDP-Fu, and GDP-X or glucose were identified at each tissue age. The only cytidine nucleotide identified in 14-, 28-, and 42-day tissue was CMP.

Confirmation that attachment of the phosphate group to the ribose moiety of the nucleotide was in the $5^{\prime}$ position was established by enzymatic hydrolysis. Inorganic phosphorus released by incubation of these nucleotides with snake venom was compared with the amount of total phosphorus present in the same specimen after hydrolysis with strong acid. An inorganic to total phosphorus $\left(\mathrm{P}_{\mathrm{i}} / \mathrm{P}_{\mathrm{t}}\right)$ ratio of 1.0 indicated that all the phosphorus had been hydrolyzed during incubation by action of specific 5'-phosphatases. Studies with standard 5 '-ribonucleotides indicated that under the specific conditions of incubation employed in these experiments the venom pyrophosphatase and 5'-nucleotidase would quantitatively release all $5^{\prime}$-phosphate. Ratios for the nucleotides isolated from 14-, 28-, and 42-dày tissue are included in Table II. Although they were less than 1.0 for some of the di- and triphosphate nucleotides, in each instance a significant fraction of the primary phosphate group was enzymatically converted to the inorganic form.

${ }^{32} P$ incorporation studies. In Table III, the mean specific activities of inorganic phosphate, the $5^{\prime}$-nucleotides, and sugar nucleotides 4 hours after in vivo administration of inorganic ${ }^{32} \mathrm{P}$ are compared at 14,28 , and 42 days. At each tissue age the specific activity of ATP was higher than that of the other 5 -nucleotides, and at 42 days it exceeded that of inorganic phosphate. The specific activity of each nucleotide and of $P_{i}$ was greatest in 14-day tissue. When these values

TABLE III

Age dependent alterations in mean and relative specific activities of 5'-ribonucleotides in sponge biopsy connective tissue

\begin{tabular}{|c|c|c|c|c|c|c|}
\hline \multirow[b]{3}{*}{$\mathbf{P}_{\mathbf{i}}$} & \multicolumn{2}{|c|}{14 days } & \multicolumn{2}{|c|}{28 days } & \multicolumn{2}{|c|}{42 days } \\
\hline & \multicolumn{6}{|c|}{ 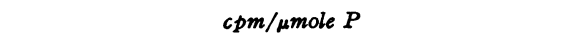 } \\
\hline & 42,100 & & 26,400 & & 16,400 & \\
\hline AMP & 13,900 & $(0.33) *$ & 15,530 & $(0.59) *$ & 11,910 & $(0.72) *$ \\
\hline ADP & 18,780 & $(0.45)$ & 16,870 & $(0.64)$ & 8,710 & $(0.53)$ \\
\hline ATP & 28,230 & $(0.67)$ & 23,020 & $(0.87)$ & 21,790 & (1.31) \\
\hline UMP & 12,000 & $(0.28)$ & 7,035 & $(0.27)$ & 10,980 & $(0.66)$ \\
\hline UDP & 16,920 & $(0.40)$ & 8,125 & $(0.31)$ & 6,690 & $(0.41)$ \\
\hline UTP & 17,200 & $(0.41)$ & 2,130 & $(0.08)$ & 4,410 & $(0.27)$ \\
\hline GMP & 8,000 & $(0.19)$ & & & 720 & $(40.0)$ \\
\hline GDP & 5,200 & $(0.12)$ & & & & \\
\hline GTP & 20,000 & $(0.48)$ & & & 3,650 & $(0.22)$ \\
\hline UDP-hexose & 17,870 & $(0.42)$ & 2,220 & $(0.08)$ & 4,370 & $(0.27)$ \\
\hline UDP-AcHm & 19,060 & $(0.45)$ & & & 10,500 & $(0.64)$ \\
\hline GPD-hexose & 17,400 & $(0.41)$ & & & 3,510 & $(0.21)$ \\
\hline
\end{tabular}

* Relative specific activity of the individual 5 '-nucleotides compared to the specific activity of the total inorganic phosphate pool at each tissue age. 
were related to the specific activity of $P_{i}$, differences relative to the inorganic phosphate pool were demonstrated for several of the $5^{\prime}$-nucleotides at 28 and 42 days. For the adenine nucleotides, UMP, and the UDP-N-acetylhexosamines relative specific activities compared with the total inorganic phosphate pool increased, whereas those of UTP, GMP, GTP, and the other sugar nucleotides decreased. These data indicate that the complex biochemical relationships of phosphate interchange known to occur among these compounds changed during maturation of the polyvinyl sponge granuloma.

Measurements of radioactivity were not made on GMP, GDP, GTP, GDP-hexose, or UDP$\mathrm{AcHm}$ at 28 days. Calculation of specific activity for GTP was not made at 42 days, since characterization of this nucleotide was incomplete. As previously indicated small amounts of AMP, UMP, GMP, ADP, and UDP were detected after final purification of the eluates from the Dowex 1 (formate) column along with their respective nucleotide di- and triphosphates in peaks $F$ to $K$. Specific activity determinations on these compounds were essentially equal to those recorded at 14, 28, and 42 days for the intact nucleotide mono- or diphosphates isolated from Dowex 1 (formate) column peaks B to G. This finding suggested that net incorporation of inorganic ${ }^{32} \mathrm{P}$ into high energy phosphate of these individual $5^{\prime}$-nucleotides at 14,28 , or 42 days preferentially followed an ordered sequence that exceeded any randomization produced by degradation or exchange reactions.

\section{Discussion}

Partial characterization of the $5^{\prime}$-nucleotide constituents of experimental connective tissue stimulated by the subcutaneous injection of carrageenin has been reported by Decker and Gross (13). The detailed findings of these investigators closely parallel the observations reported here for connective tissue stimulated by subcutaneous implantation of polyvinyl sponge (28). By using agar implantation to stimulate connective tissue formation in rats, Tetsuka and Konno (29) have studied ${ }^{32} \mathrm{P}$ incorporation into the ribonucleic acids. Although their study was directed toward identification of $2^{\prime}$-, $3^{\prime}$-nucleotide base composi- tion and its presumed relationship to collagen synthesis, they did observe prompt incorporation of isotope into 5 '-ribonucleotides and sugar phosphates. These observations complement the present investigation and demonstrate that 5 'ribonucleotides and several of the sugar nucleotide intermediates that had been shown to be involved in mucopolysaccharide, glycoprotein, and glycolipid synthesis in other systems $(8,10,11)$ can be isolated from connective tissues stimulated by three different experimental procedures.

Of critical importance to proper interpretation of the present data was an evaluation of the methods used in this investigation to isolate and identify the $5^{\prime}$-ribonucleotides. Satisfactory reproducibility of the fractionation procedures, although complex, has been demonstrated in the two 14-day studies and further confirmed by the experience with duplicate experiments reported in another study (30). The net increase in UDP-N-acetylglucosamine + UDP-N-acetylgalactosamine with tissue age appears to be an accurate reflection of the internal changes in sugar nucleotide composition that occur during growth and maturation of sponge biopsy connective tissue. Isolation and partial characterization of only trace amounts of UDP-glucuronic acid could have resulted from the known difference in chemical stability of this compound to the procedures used to separate and identify the other $5^{\prime}$-nucleotides (10). Similarly, CMP-N-acetylneuraminic acid is extremely labile and may have been present but undergoing spontaneous degradation during fractionation of the acid soluble tissue extract (25). For this reason equally important changes in these or other sugar nucleotide constituents may have gone undetected in the present study.

One explanation for the observed increase in the amount of UDP-N-acetylhexosamines present at 28 and 42 days could be a decrease in de novo synthesis of mucopolysaccharides and glycoproteins. All previous chemical studies carried out on this tissue $(6,14,31)$ indicate that formation of extracellular constituents reaches maximal concentrations between 28 and 42 days after implantation. In this situation, concentration of the final end products or their rate of removal could determine the rate of synthesis of essential precursors (32). Alternatively, it has recently been suggested (33-35) that individual sugar nucleo- 
tides, including UDP-N-acetylglucosamine (34), may control their own rate of synthesis by "feedback inhibition." Under these circumstances, different quantities of the individual nucleotidelinked sugars have been found to accumulate (12). It has been postulated that regulatory mechanisms of this type would spare the excessive utilization of high energy phosphate when incorporation of activated precursors into final macromolecular products was blocked for any reason $(34,35)$. Changes in mucopolysaccharide concentrations have been reported to occur in several specialized forms of connective tissue with increased tissue age $(2,3,36)$. Perhaps the observed increase in UDP-N-acetylhexosamines noted in sponge biopsy connective tissue and knowledge of the biochemical control of sugar nucleotide metabolism may ultimately prove to be related to the age dependent changes in the concentrations of specific extracellular constituents of connective tissue. Further examination of their role in connective tissue metabolism may broaden our understanding of the physiopathology of the processes of aging and the diseases of connective tissue.

\section{Summary}

The $5^{\prime}$-ribonucleotides present in acid soluble extracts of rapidly growing connective tissue stimulated by subcutaneous polyvinyl sponge implantation have been isolated and partially characterized. The in vivo incorporation of inorganic ${ }^{32} \mathrm{P}$ into these activated chemical intermediates has also been determined. The concentration of uridine diphosphate (UDP)- $\mathrm{N}$-acetylglucosamine + UDP-N-acetylgalactosamine increased from 1.2 to $2.5 \mu$ moles per $100 \mathrm{~g}$ between 14 and 42 days after implantation. During this time, the ${ }^{32} \mathrm{P}$ specific activity of the uridine, guanosine, and sugar nucleotides decreased with increase in tissue age. Except for uridine monophosphate and the UDP-N-acetylhexosamines the relative specific activity compared to that of the inorganic phosphate pool also decreased during this time interval. The specific activity of the adenine nucleotides remained essentially stable, whereas their relative specific activities increased during connective tissue organization of the polyvinyl sponge implant.
In this study several nucleotide-linked sugars currently recognized as intermediates in biosynthesis of mucopolysaccharides and glycoproteins have been isolated and identified. The changing concentration of UDP-N-acetylglucosamine + UDP-N-acetylgalactosamine may indicate that these nucleotides play an important role in regulation of the anabolic pathways that lead to synthesis of several of the ground substance constituents of connective tissue.

\section{Acknowledgments}

The author wishes to express his appreciation to Drs. Bruce A. Bartholomew, G. William Jourdian, and Saul Roseman, Rackham Arthritis Research Unit, The University of Michigan, for their suggestions and criticisms during these investigations.

\section{References}

1. Jackson, D. S., J. H. Yardley, S. F. Jackson, and B. S. Gould. What is the role of connective tissue cells in the formation of the extracellular components of the tissue? in The Biology of Connective Tissue Cells, Conference Series No. 7, C. W. Castor, D. J. Merchant, and L. E. Shulman, Eds. New York, Arthritis and Rheumatism Foundation, 1962, p. 172.

2. Kaplan, D., and K. Meyer. Ageing of human cartilage. Nature (Lond.) 1959, 183, 1267.

3. Kaplan, D., and K. Meyer. Mucopolysaccharides of aorta at various ages. Proc. Soc. exp. Biol. (N. Y.) $1960,105,78$.

4. Robertson, W. van B., and B. Schwartz. Ascorbic acid and the formation of collagen. J. biol. Chem. 1953, 201, 689.

5. Udupa, K. N., J. F. Woessner, and J. E. Dunphy. The effect of methionine on the production of mucopolysaccharides and collagen in healing wounds of protein-depleted animals. Surg. Gynec. Obstet. 1956, 102, 639.

6. Woessner, J. F., and R. J. Boucek. Connective tissue development in subcutaneously implanted polyvinyl sponge. 1. Biochemical changes during development. Arch. Biochem. 1961, 93, 85.

7. Weiss, S. B. Biosynthesis of ribopolynucleotides. Fed. Proc. 1962, 21, 120.

8. Leloir, L. F. The biosynthesis of polysaccharides in Proceedings of the Plenary Sessions, Sixth International Congress of Biochemistry, 1st. ed., W. H. Stein, J. S. Fruton, B. L. Horecker, and A. White, Eds. New York, Rockefeller University Press, 1964, vol. 33, p. 15.

9. Kennedy, E. P. Biosynthesis of complex lipids. Fed. Proc. 1961, 20, 934.

10. Roseman, S. Metabolism of connective tissue. Ann. Rev. Biochem. 1959, 28, 545. 
11. Roseman, S. Metabolism of sialic acids and D-mannosamine. Fed. Proc. 1962, 21, 1075.

12. Neufeld, E. F., and V. Ginsburg. Carbohydrate metabolism. Ann. Rev. Biochem. 1965, 34, 297.

13. Decker, J. L., and J. Gross. The acid soluble nucleotides of growing connective tissue. Arthr. and Rheum. 1958, 1, 276.

14. Bole, G. G., Jr., and W. D. Robinson. Histochemical and biochemical variations in the connective tissue in polyvinyl alcohol sponge implants. J. Lab. clin. Med. 1962, 59, 713.

15. Hurlbert, R. B., H. Schmitz, A. F. Brumm, and V. R. Potter. Nucleotide metabolism. II. Chromatographic separation of acid-soluble nucleotides. J. biol. Chem. 1954, 209, 23.

16. Davis, J. R., and R. N. Morris. Rapid colorimetric determination of adenine compounds. Analyt. Biochem. 1963, 5, 64.

17. Lowry, O. H., N. J. Rosebrough, A. L. Farr, and R. J. Randall. Protein measurement with the Folin phenol reagent. J. biol. Chem. 1951, 193, 265.

18. Denamur, R., G. Fauconneau, and G. Guntz. Les nucléotides acido-solubles du lait de brebis. C. $\mathrm{R}$. Acad. Sci. (Paris) 1958, 246, 492.

19. Wilken, D. R., and R. G. Hansen. A nucleotide-peptide isolated from bovine liver. J. biol. Chem. 1961, 236, 1051.

20. Bartlett, G. R. Methods for the isolation of glycolytic intermediates by column chromatography with ion exchange resins. J. biol. Chem. 1959, 234, 459.

21. Pabst Laboratories Circular OR-10, Milwaukee, 1956, p. 21.

22. Heppel, L. A., and R. J. Hilmoe. Purification and properties of 5'-nucleotidase. J. biol. Chem. 1951, 188, 665.

23. Gordon, H. T., W. Thornburg, and L. N. Werum. Rapid paper chromatography of carbohydrates and related compounds. Analyt. Chem. 1956, 28, 849.

24. Jourdian, G. W., and S. Roseman. The sialic acids. II. Preparation of N-glycolylhexosamines, $N$-glycolylhexosamine-6-phosphates, glycolyl coenzyme A, and glycolyl glutathione. J. biol. Chem. 1962, 237, 2442.
25. Molnar, J., G. B. Robinson, and R. J. Winzler. The biosynthesis of glycoproteins. III. Glucosamine intermediates in plasma glycoprotein synthesis in livers of puromycin-treated rats. J. biol. Chem. 1964, 239, 3157.

26. Gardell, S. Separation on Dowex 50 ion exchange resin of glucosamine and galactosamine and their quantitative determination. Acta chem. scand. 1953, 7, 207.

27. Roseman, S., and I. Daffner. Colorimetric method for determination of glucosamine and galactosamine. Analyt. Chem. 1956, 28, 1743.

28. Decker, J. L. Personal communication.

29. Tetsuka, T., and K. Konno. Studies on the connective tissue. II. Nucleic acids and the related substances in the granuloma induced by the agar implantation. J. Biochem. (Tokyo) 1963, 54, 432.

30. Bole, G. G., Jr. A comparative study of the effect of hydrocortisone on the sugar nucleotide content of sponge biopsy connective tissue and the liver (abstract). J. Lab. clin. Med. 1965, 66, 855.

31. Bollet, A. J., J. F. Goodwin, W. F. Simpson, and D. V. Anderson. Mucopolysaccharide, protein and desoxyribosenucleic acid concentration of granulation tissue induced by polyvinyl sponges. Proc. Soc. exp. Biol. (N. Y.) 1958, 99, 418.

32. Moyed, H. S., and H. E. Umbarger. Regulation of biosynthetic pathways. Physiol. Rev. 1962, 42, 444.

33. Neufeld, E. F., and C. W. Hall. Inhibition of UDP$D$-glucose dehydrogenase by UDP- $D$-xylose: a possible regulatory mechanism. Biochem. biophys. Res. Commun. 1965, 19, 456.

34. Kornfeld, S., R. Kornfeld, E. F. Neufeld, and P. J. O'Brien. The feedback control of sugar nucleotide biosynthesis in liver. Proc. nat. Acad. Sci. (Wash.) 1964, 52, 371.

35. Mayer, R. M., and V. Ginsburg. Purification and properties of cytidine diphosphate $D$-glucose pyrophosphorylase from Salmonella paratyphi A. J. biol. Chem. 1965, 240, 1900.

36. Bollet, A. J., J. R. Handy, and B. C. Sturgill. Chondroitin sulfate concentration and proteinpolysaccharide composition of articular cartilage in osteoarthritis. J. clin. Invest. 1963, 42, 853. 